\title{
The 3R principle: advancing clinical application of human pluripotent stem cells
}

\author{
Michael D O'Connor*
}

\begin{abstract}
The first derivation of human embryonic stem cells brought with it a clear understanding that animal models of human disease might be replaced by an unlimited supply of human cells for research, drug discovery, and drug development. With the advent of clinical trials using human pluripotent stem cellbased therapies, it is both timely and relevant to reflect on factors that will facilitate future translation of this technology. Human pluripotent cells are increasingly being used to investigate the molecular mechanisms that underpin normal and pathological human development. Their differentiated progeny are also being used to identify novel pharmaceuticals, to screen for toxic effects of known chemicals, and to investigate cell or tissue transplantation strategies. The intrinsic assumption of these research efforts is that the information gained from these studies will be more accurate, and therefore of greater relevance, than traditional investigations based on animal models of human disease and injury. This review will therefore evaluate how animals and animal-derived products are used for human pluripotent stem cell research, and will indicate how efforts to further reduce or remove animals and animal products from this research will increase the clinical translation of human pluripotent stem cell technologies through drug discovery, toxicology screening, and cell replacement therapies.
\end{abstract}

\section{Introduction}

Human pluripotent stem (PS) cells are providing a plentiful supply of differentiated human cell types for developmental biology, drug discovery, and clinical applications. The very fact these are human cells brings an implicit opportunity to decrease our reliance upon traditional

*Correspondence: m.oconnor@uws.edu.au

School of Medicine, University of Western Sydney, Molecular Medicine Research Group, Locked Bag 1797, Penrith South DC, NSW 1797, Australia animal research models of human disease and injury. In the USA alone, over 1 million dogs, cats, primates, rabbits, and other large animals are used for research each year [1]. When rats and mice are included, the number is estimated to be in the tens of millions of animals per year. In Europe, almost 10 million vertebrate animals are used annually for research, and changes to the European Commission REACH legislation (Registration, Evaluation, Authorisation and Restriction of Chemical substances) could result in an additional 3.9 million test animals being required over the next 11 years [2].

Given the time and financial costs associated with animal models, as well as the fact that they often do not accurately predict the toxicity or efficacy of new treatments and products in humans [3-5], it is timely to analyse the various fields of human PS cell research while keeping in mind the $3 R$ principle of ethical animal use in research: to reduce, replace, or refine animal usage [6]. When viewed from this perspective there are clear avenues to help realise more quickly the commercial potential of human PS cells in biotechnology and clinical research, while at the same time reducing our reliance upon imperfect animal research models.

A variety of human PS cell types are available for research, including embryonic stem (ES) cells, induced pluripotent stem (iPS) cells, embryonal carcinoma cells, and embryonal germ cells. Human ES and iPS cells are the most likely of these pluripotent cells to have direct clinical application; however, all four human pluripotent cell types are considered relevant to investigations of molecular development and novel drug screening. Use of these human PS cells can be divided into three broad yet overlapping areas: pluripotent cell generation and maintenance; generation and purification of differentiated cell types; and research and clinical application of human PS cells and their differentiated derivatives. Each of these research areas has used, or continues to use, animals and/ or animal-derived products. However, there is growing recognition that, where possible, finding non-animalbased alternatives will help to more quickly achieve the full potential of human PS cells in each research area [7-10]. As described below, the translation of PS cell technology from academic research to biotechnology 
applications has already begun. This includes use of the embryonic stem cell test (EST) to predict embryotoxicity [9] and clinical trials using human ES cell-derived oligodendrocytes and retinal pigment epithelium (RPE) $[11,12]$. These early successes suggest that further application of the $3 \mathrm{R}$ principle to human PS cell research will be economically, clinically, and ethically useful.

\section{Removal of animal products delivers high-quality pluripotent cell cultures}

Traditionally, maintenance of human PS cells required co-culture with mouse embryonic fibroblasts in medium containing bovine serum in order to keep the cells in a pluripotent state [13]. Difficulties with this system - in particular, sourcing suitably supportive batches of fibroblasts and serum - made this approach highly specialised, time consuming, and expensive. Even with validated batches of these reagents, variable levels of spontaneous differentiation routinely occurred [7]. This meant that maintaining reproducibly undifferentiated cultures on a weekly basis was challenging. Initial attempts to minimise or eliminate these batch-variable animal products were partially successful, and included elimination of direct feeder cell contact through the use of feeder conditioned medium [14], development of a moderately less variable serum replacement [8], and the establishment of human feeder cells [15].

Continued research into the growth factor requirements of human PS cells led to the publication of a variety of defined, feeder-independent media, some of which are fully xeno free [7]. A multi-laboratory international comparison of eight different feeder-free human PS cell media recently demonstrated that two of these media are able to support mid-term to long-term culture of multiple human PS cell lines across multiple groups [16]. These reagents have greatly reduced inter-laboratory variability and thus have made human PS cell research more efficient and reliable.

Coincident with the development of xeno-free human PS cell culture media, efforts have also been focused on developing xeno-free culture surfaces. Initial reliance upon mouse embryonic fibroblasts for cell attachment was replaced with animal-derived extracellular matrices [14] or human feeder cells [15]. More recently, xeno-free chemical or recombinant extracellular matrices have been developed that are suitable for use with xeno-free human PS cell culture media [17]. While the cost of these media and culture surfaces was initially a factor limiting their widespread use, this is becoming less of an issue as multiple competing products are being commercialised.

Application of the $3 \mathrm{R}$ principle has thus removed animal products from human PS cell maintenance media and culture surfaces while having multiple additional benefits, including increased ease of handling, improved culture quality (that is, markedly reduced levels of spontaneous differentiation), and generation of a more clinically appropriate culture environment.

\section{Xeno-free human pluripotent stem cell generation}

Xeno-free culture reagents for human PS cell maintenance are now being applied for the generation of clinically relevant, xeno-free human ES and iPS cell lines $[7,18]$. These cell lines display defining characteristics of pluripotency, such as self-renewal, tri-lineage differentiation capacity, and karyotypic stability. For over a decade, the teratoma assay has been the most widely used and accepted method to demonstrate multi-lineage differentiation capacity of human PS cells $[19,20]$. To perform this assay, PS cells are transplanted into immunocompromised mice (under the kidney capsule, into the testis, or subcutaneously) to induce their differentiation to derivatives of endoderm, mesoderm, and ectoderm. However, the lack of sensitivity of this assay means it is essentially nonquantitative with respect to the input cell number $[19,20]$. Moreover, the assay is labour and time intensive (taking 2 to 3 months to complete), and analysis of the differentiated cells produced is almost always qualitative (that is, simply reporting whether or not certain cell types are found but not the relative ratios of these). Accordingly, there is a growing consensus that these limitations necessitate the development of improved replacement pluripotency assays [21]. This is particularly relevant given the advent of human iPS cells, and the associated pluripotency assessment that will be required to enable clinical application of such patientspecific cells.

\section{Xeno-free human pluripotent stem cell characterisation}

Replacing the teratoma assay will require the establishment of methods that comprehensively and quantitatively define a broad range of phenotypic and functional parameters characteristic of pluripotent cells. Attempts to do this via genome-wide expression profiling of undifferentiated human ES and iPS cells has led to in silico methods, such as PluriNet [22], which can catalogue and compare the gene expression profiles of newly derived cell lines. Encouragingly, these methods can accurately distinguish pluripotent cells from nonpluripotent cells, suggesting they may provide an alternate method to teratoma formation for pluripotent cell classification. Not all human PS cells have equivalent differentiation potential, however, even though they have similar gene expression profiles [23]. Accurately assessing functional pluripotency (that is, the capacity to produce particular differentiated cell types) is thus currently not possible on the basis of gene expression or epigenetics alone. To address this, animal-free in vitro methods of teratoma 
formation are being explored. One recent study examined the spontaneous differentiation of human ES cells in a perfused three-dimensional multi-compartment bioreactor [24]. This system reported generation of embryoid bodies with histological and transcriptional features similar to those that develop in the mouse teratoma assay. However, this approach still relies upon histological analysis to infer pluripotency from the identification of multiple differentiated cell types. As histological assessment is time and labour intensive and does not assess differentiated cell function, this may limit the utility of in vitro teratoma formation for human PS cell characterisation.

Interestingly, an alternate animal-free approach for assessing the differentiation capacity of new human PS cell lines is emerging. With this approach one or two desired differentiated cell types are rigorously and quantitatively analysed using a broad range of cell-type specific assays. For example, human PS cell-derived RPE is beginning to be assessed using a range of assays to establish how closely its characteristics resemble primary human RPE. This has led to the emergence of the 4P criteria for RPE: (i) pigmentation and (ii) polygonal morphology, assessed via light microscopy and immunofluorescence (for example, for TRP-1 and claudin 19, respectively); (iii) cell polarity, assessed via immunofluorescence (for example, Ezrin), transmission electron microscopy (to look for apical projections), or transepithelial resistance measurements; and (iv) phagocytic capacity, assessed by the ability to uptake fluorescently-labelled beads or photoreceptor fragments $[25,26]$. Importantly, such comprehensive assessment provides a detailed phenotypic and functional baseline for human PS cellderived RPE compared with the known behaviour of primary human RPE. In doing so, this approach goes a significant way towards defining the suitability of human PS cell-derived RPE for both research and clinical applications. Future development of similar assay panels for other differentiated cell types will enable a reduction in the use of animals in research and, equally importantly, will enable robust phenotypic and functional cell characterisation that increases confidence in the data generated [9].

\section{Improved drug discovery and development using pluripotent stem cells}

Validated panels of PS cell-based in vitro assays are also being applied to drug discovery and toxicology assessments [10,27-37]. This application is due not only to the ethical and economic issues associated with animal experimentation, but also because animal models do not always accurately predict the efficacy and/or safety of substances in humans [3-5]. Various groups are investigating the potential of human PS cell-derived hepatocytes and cardiomyocytes for drug discovery [32,33], while human iPS cell-derived cardiomyocytes are already commercially available for research and drug screening (for example, Cellular Dynamics, GE Healthcare, Lonza). Improved methods for generating and purifying a wider variety of differentiated cell types from human PS cells may ultimately enable in vitro toxicity testing of all human cell and/or tissue types.

Additional strategies are also being developed to eliminate inappropriate drugs, chemicals and cosmetics earlier during commercial development according to their toxicity profile in PS cell-based assays. Traditionally, a range of animal models have been used to test the efficacy and toxicity of these substances, including mice, rats, rabbits, pigs, dogs, and non-human primates [38]. However, significant international interest from scientists, ethicists, and regulatory bodies is driving the development of replacement in vitro assays [37,39]. For example, the mouse EST has already been validated by the European Centre for the Validation of Alternative Methods as a viable alternative assay for embryotoxicity $[9,10]$. This 7 to 10 -day assay makes use of undifferentiated ES cells, ES cell-derived cardiomyocytes, and $\mathrm{NIH} 3 \mathrm{~T} 3$ cells, together with statistical assessment of endpoints that include cell morphology, viability, beating frequency, and more recently gene expression and proteomic analyses.

Application of this assay to a range of known toxicants predicted embryotoxicity with an overall accuracy of $80 \%$, with $100 \%$ accuracy for strong embryotoxicants $[10,40]$. While the overall predictive capacity is lower than the ideal of $100 \%$, it has nevertheless been sufficient (relatively high true positives, low false positives, and low false negatives) for its use as an animal replacement assay by a number of large international pharmaceutical companies (for example, Pfizer) [10]. Moreover, its application to compliance testing for the European Commission $\mathrm{REACH}$ legislation is predicted to reduce animal usage by $\sim 30 \%$ (that is, 1.3 million animals), and thus greatly reduce the cost of this testing while still providing the necessary testing rigour [2].

The success of the EST has led to other studies aimed at incorporating a wider array of differentiated cell types to enable toxicity assessment for other human tissues. For instance, incorporation of ES cell-derived neural and bone cells is being investigated for the EST $[9,41]$. The drug development opportunities associated with the ability to reproducibly generate large, pure populations of normal (or diseased) differentiated human cells are clear. Moreover, as improvements in differentiation strategies enable the production of functional human tissue in vitro, the opportunities for drug and toxicology screening will increase. Given that all human organs can experience adverse reactions due to exposure to inappropriate drugs or chemicals, there is much scope for continued 
development and commercial application of novel human PS cell-based toxicology systems to replace currently used animal models [42].

\section{Xeno-free differentiation of human pluripotent stem cells}

Establishing simple and efficient methods for differentiating human PS cells into desired specialised cell types has become a major focus of human PS cell research. Initial efforts in this area relied mainly upon adapting methods used for mouse PS cell differentiation [41]. While these studies showed that in vitro differentiation of human PS cells was possible, the yield and purity of the desired differentiated cells were routinely low due to the uncontrolled production of other, undesired cell types. One reason for this indiscriminate differentiation was (and still is) the use of poorly characterised animal products to initiate and/or propagate the differentiation process (for example, serum, feeder cells, cell substrates, and so forth) [41].

These initial differentiation efforts have evolved into attempts at developing multi-step differentiation protocols that aim to mimic in vitro the cell type-specific sequence of events that occur during embryogenesis. For example, this directed approach to PS cell differentiation has been used to obtain pancreatic cells [43], neurons [44], RPE [25,26], and ocular lens cells [45]. To a greater or lesser extent, these protocols have been partially successful in that they produce in a step-wise manner at least some of the cellular precursors required as well as the final cell type of interest. However, these directeddifferentiation protocols remain suboptimal due to the simultaneous production of varying numbers of undesired cell types.

Until these methods are optimised, purification strategies are needed to obtain the desired cell type free from undesired contaminating cells. Cell purification is typically achieved via manual excision, flow cytometry, and/or reporter plasmids (that is, cDNA constructs containing cell type-specific promoters that drive expression of antibiotic-resistance and/or fluorescence genes). These purification strategies add to the cost, processing time and specialised expertise required to obtain the cell types of interest. Further optimisation of directed-differentiation protocols, by continued replacement of poorlydefined animal products with consecutive application of defined recombinant growth factors or small molecules, will improve the yield and purity of desired differentiated cell types [41]. This process of protocol optimisation will probably continue to be iterative, as empirical testing of protocol modifications leads to further rounds of cell biology discovery and subsequent protocol optimisation.

While it will be important to further optimise methods for differentiating human PS cells into specific individual cell types, there is also much interest in using pluripotent cells to generate complex functional tissues in vitro. To date, in vitro tissues that are morphologically and functionally similar to the liver [46], skin [47], retina [48], heart [49], lung [50], and ocular lens [51,52] have been generated from various pluripotent or other cell sources. These efforts face the challenge of not only producing the correct cell types present in a particular tissue, but also having them form the correct three-dimensional structure required for normal tissue functionality. Critical to these efforts is the development of appropriate extracellular matrix analogues that can be fabricated into effective tissue shapes [50]. These matrices may also need to stimulate localised growth of different cell types (for example, to allow formation of functional blood vessels where necessary within an in vitro tissue). Replacing animal-derived growth factors and extracellular matrices with defined recombinant reagents or small molecules will accelerate these efforts at in vitro tissue production. In turn, this will open up a wide range of new possibilities for cell replacement and drug discovery.

\section{Validation of pluripotent stem cell-derived technology}

In the short term to mid-term, animal models of development will continue being investigated to provide clues for the molecular events involved in cell and tissue formation. Additionally, live animal cell-function assays will continue being used to define the functional properties of human PS cell progeny, by assessing whether these cells can properly integrate and correct a disease or injury in vivo [41]. This assessment is evidenced by the increasing number of human PS cell derivatives that are being assessed in animal models, including neurons to correct spinal cord injury [53], blood cells for understanding haematopoietic diseases [54], and retinal cells for blindness [55]. In the foreseeable future, many fields will continue to require transplantation into animal models to assess differentiated cell function, particularly if the differentiated cells are for clinical transplantation.

Given the cellular and molecular differences between humans and animals, expanded assay panels for in vitro cell phenotype and function will become increasingly important in reducing the use and cost of animal-based assays while increasing the quality of data obtained [9]. The EST for embryotoxicity, new derivative ESTs, and the 4P assays for PS cell-derived RPE are examples of how PS cell-based in vitro assays are beginning to replace in vivo animal models. Key technical factors driving this replacement are an ability to purify large quantities of the test cell type for observation and measurement, an understanding of how the test cell type normally functions in vivo, and defined assay endpoints that accurately detect cell phenotype or function. Together, 
these elements enable comparison of the in vitro cell performance with known in vivo behaviour of the same cell type, thus enabling a determination of whether a proposed PS cell-based assay can be validated as a replacement of a current animal-based assay. Technological improvements are also aiding development of these in vitro animal replacement assays, such as highcontent imaging, novel cell culture substrates, and the ability to produce complex in vitro tissues that mimic performance of whole tissues as opposed to isolated individual cell types [46-50]. Rigorous assessment of these emergent in vitro assays will be critical for ensuring that only assays with demonstrable utility and accuracy gain acceptance. Moreover, development of these animal replacement assays will be aided by consultation with end users (for example, pharmaceutical companies, policy advisory bodies, and so forth), who will ultimately determine whether such assays provide sufficient financial and/or accuracy advantages over existing animalbased assays to warrant widespread use [39].

\section{Clinical application of human pluripotent stem cell-derived therapies}

One of the most widely anticipated applications of human PS cell technology is the development of new cell replacement therapies. Early concerns about the clinical translation of human ES cell derivatives revolved around the potential transfer of pathogens and immunogens from animal products such as the mouse embryonic fibroblasts traditionally used for pluripotent cell maintenance [56]. For example, human ES cells maintained using mouse embryonic fibroblasts and/or animalderived serum replacements were shown to incorporate an immunogenic nonhuman sialic acid (Neu5Gc) capable of inducing an immune response in vitro [56]. Although other studies questioned the extent of Neu5Gc contamination in human ES cell cultures and its immunogenic potential [57-59], significant efforts continue to be made to enable animal product-free culture of human pluripotent cells and their derivatives. As mentioned above, this has led to the development of a variety of animal product replacements including human feeder cells [15], defined media [7], and chemical or recombinant extracellular matrices [17].

Three clinical trials have to date been initiated using purified human ES cell derivatives: oligodendrocytes for spinal cord injury [11], and RPE for age-related macular degeneration and Stargardt's macular dystrophy [12]. The phase I oligodendrocyte trial recently ceased taking new enrolments due to Geron's controversial strategic financial decision to move out of the stem cell field in favour of developing in-house anti-cancer drugs [60]. However, new enrolments in the two RPE trials are set to continue on the basis of encouraging preliminary safety data from a single patient in each trial [12]. As these trials progress, continued human PS cell research aimed at further eliminating animal product will both increase the efficiency of differentiation protocols and limit the potential adverse clinical consequences of animal product use. In turn, these studies will aid the clinical translation of a wider variety of human PS cell-derived cell types.

\section{Conclusion}

The potential for human PS cells to increase our understanding of human development and to provide differentiated cells for drug screening, toxicology studies, and cell replacement therapies is widely acknowledged. Significant technical hurdles must still be overcome, but realisation of this potential is increasingly becoming reality. A small number of commercially produced differentiated human PS cell types are already in use for drug development or clinical applications, and it is reasonable to expect that this will increase as a greater variety of human PS cell-derived cells and tissues become available over the coming years. Owing to the experimental variation, cost, and clinical barriers that arise through the use of animals and animal products, continued development of human PS cell technology will significantly benefit from refinement, reduction, and/or replacement of these animal-based methods. The goals of many human PS cell researchers are therefore highly consistent with the 3R principle for the ethical use of animals in research. Moreover, optimisation of human PS cell technology based on the 3R principle will increasingly provide clear commercial opportunities for the biotechnology and clinical sectors, including: development of chemically defined reagents for human PS cell generation, maintenance, and differentiation; improved cell detection and purification strategies; and purified cell types for transplantation and in vitro drug discovery and toxicity assays.

\footnotetext{
Abbreviations

ES, embryonic stem; EST, embryonic stem cell test; iPS, induced pluripotent stem; 4P, pigmentation, polygonal morphology, cell polarity, and phagocytic capacity; PS, pluripotent stem; $3 R$, reduce, refine, replace; $R P E$, retinal pigment epithelium.

Competing interests

MDO has previously received research funding from the Medical Advances Without Animals Trust.

Published: 8 March 2013

References

1. Animal and Plant Health Inspection Service: Animal Care Annual Report of Activities. Washington DC: United States Department of Agriculture; 2007.

2. van der Jagt K, Munn S, Tørsløv J, de Bruijn J: Alternative Approaches can Reduce the Use of Test Animals under REACH. Addendum to the Report: Assessment of Additional Testing needs Under REACH Effects of (Q)SARS, Risk Based Testing and Voluntary Industry Initiatives. @ European Communities, 2004. Printed in Italy.

3. Knight A: Systematic reviews of animal experiments demonstrate poor
} 
contributions toward human healthcare. Rev Recent Clin Trials 2008, 3:89-96.

4. Wall RJ, Shani M: Are animal models as good as we think? Theriogenology 2008, 69:2-9.

5. Eastwood D, Findlay L, Poole S, Bird C, Wadhwa M, Moore M, Burns C, Thorpe R, Stebbings R: Monoclonal antibody TGN1412 trial failure explained by species differences in CD28 expression on $\mathrm{CD}^{+}$effector memory T-cells. Br J Pharmacol 2010, 161:512-526.

6. Russell WMS, Burch RL: The Principles of Humane Experimental Techniques. London: Methuen; 1959.

7. Ludwig TE, Levenstein ME, Jones JM, Berggren WT, Mitchen ER, Frane JL, Crandall $\sqcup$, Daigh CA, Conard KR, Piekarczyk MS, Llanas RA, Thomson JA Derivation of human embryonic stem cells in defined conditions. Nat Biotechnol 2006, 24:185-187.

8. Amit M, Shariki C, Margulets V, Itskovitz-Eldor J: Feeder layer- and serum-free culture of human embryonic stem cells. Biol Reprod 2004, 70:837-845.

9. Theunissen PT, Piersma AH: Innovative approaches in the embryonic stem cell test (EST). Front Biosci 2012, 17:1965-1975.

10. Seiler AE, Spielmann H: The validated embryonic stem cell test to predict embryotoxicity in vitro. Nat Protoc 2011, 6:961-978.

11. Sharp J, Keirstead HS: Therapeutic applications of oligodendrocyte precursors derived from human embryonic stem cells. Curr Opin Biotechnol 2007, 18:434-440.

12. Schwartz SD, Hubschman JP, Heilwell G, Franco-Cardenas V, Pan CK, Ostrick RM, Mickunas E, Gay R, Klimanskaya I, Lanza R: Embryonic stem cell trials for macular degeneration: a preliminary report. Lancet 2012, 379:713-720.

13. Thomson JA, Itskovitz-Eldor J, Shapiro SS, Waknitz MA, Swiergiel JJ, Marshall VS, Jones JM: Embryonic stem cell lines derived from human blastocysts. Science 1998, 282:1145-1147.

14. Xu C, Inokuma MS, Denham J, Golds K, Kundu P, Gold JD, Carpenter MK Feeder-free growth of undifferentiated human embryonic stem cells. Nat Biotechnol 2001, 19:971-974.

15. Stacey GN, Cobo F, Nieto A, Talavera P, Healy L, Concha A: The development of 'feeder' cells for the preparation of clinical grade $h E S$ cell lines: challenges and solutions. J Biotechno/ 2006, 125:583-588.

16. International Stem Cell Initiative Consortium; Akopian V, Andrews PW, Beil S, Benvenisty N, Brehm J, Christie M, Ford A, Fox V, Gokhale PJ, Healy L, Holm F, Hovatta O, Knowles BB, Ludwig TE, McKay RD, Miyazaki T, Nakatsuji N, Oh SK, Pera MF, Rossant J, Stacey GN, Suemori H: Comparison of defined culture systems for feeder cell free propagation of human embryonic stem cells. In Vitro Cell Dev Biol Anim 2010, 46:247-258.

17. Couture LA: Scalable pluripotent stem cell culture. Nat Biotechno/ 2010, 28:562-563.

18. Ohmine S, Dietz AB, Deeds MC, Hartjes KA, Miller DR, Thatava T, Sakuma T, Kudva YC, Ikeda Y: Induced pluripotent stem cells from GMP-grade hematopoietic progenitor cells and mononuclear myeloid cells. Stem Cell Res Ther 2011, 2:46.

19. O'Connor MD, Kardel MD, Eaves CJ: Functional assays for human embryonic stem cell pluripotency. Methods Mol Biol 2011, 690:67-80

20. Ungrin $M, O^{\prime}$ Connor MD, Eaves CJ, Zandstra PW: Phenotypic analysis of human embryonic stem cells. Curr Protoc Stem Cell Biol 2007, 2:3.1-3.25.

21. Dolgin E: Putting stem cells to the test. Nat Med 2010, 16:1354-1357.

22. Muller FJ, Laurent LC, Kostka D, Ulitsky I, Williams R, Lu C, Park IH, Rao MS, Shamir R, Schwartz PH, Schmidt NO, Loring JF: Regulatory networks define phenotypic classes of human stem cell lines. Nature 2008, 455:401-405.

23. Sullivan GJ, Bai Y, Fletcher J, Wilmut I: Induced pluripotent stem cells: epigenetic memories and practical implications. Mol Hum Reprod 2010, 16:880-885.

24. Stachelscheid H, Wulf-Goldenberg A, Eckert K, Jensen J, Edsbagge J, Bjorquist P, Rivero M, Strehl R, Jozefczuk J, Prigione A, Adjaye J, Urbaniak T, Bussmann P, Zeilinger K, Gerlach JC: Teratoma formation of human embryonic stem cells in three-dimensional perfusion culture bioreactors. J Tissue Eng Regen Med 2012. doi: 10.1002/term.1467 [Epub ahead of print]

25. Carr AJ, Vugler A, Lawrence J, Chen LL, Ahmado A, Chen FK, Semo M, Gias C, da Cruz L, Moore HD, Walsh J, Coffey PJ: Molecular characterization and functional analysis of phagocytosis by human embryonic stem cellderived RPE cells using a novel human retinal assay. Mol Vis 2009 15:283-295.

26. Idelson M, Alper R, Obolensky A, Ben-Shushan E, Hemo I, Yachimovich-Cohen N, Khaner H, Smith Y, Wiser O, Gropp M, Cohen MA, Even-Ram S, BermanZaken Y, Matzrafi L, Rechavi G, Banin E, Reubinoff B: Directed differentiation of human embryonic stem cells into functional retinal pigment epithelium cells. Cell Stem Cell 2009, 5:396-408.

27. Das AK, Pal R: Induced pluripotent stem cells (iPSCs): the emergence of a new champion in stem cell technology-driven biomedical applications. J Tissue Eng Regen Med 2010, 4:413-421.

28. West PR, Weir AM, Smith AM, Donley EL, Cezar GG: Predicting human developmental toxicity of pharmaceuticals using human embryonic stem cells and metabolomics. Toxicol App/ Pharmacol 2010, 247:18-27.

29. Ebert $A D$, Svendsen $C N$ : Human stem cells and drug screening: opportunities and challenges. Nat Rev Drug Discov 2010, 9:367-372.

30. Winkler J, Sotiriadou I, Chen S, Hescheler J, Sachinidis A: The potential of embryonic stem cells combined with -omics technologies as mode systems for toxicology. Curr Med Chem 2009, 16:4814-4827.

31. Vojnits K, Bremer S: Challenges of using pluripotent stem cells for safety assessments of substances. Toxicology 2010, 270:10-17.

32. Sartipy P, Bjorquist $P$, Strehl R, Hyllner J: The application of human embryonic stem cell technologies to drug discovery. Drug Discov Today 2007, 12:688-699.

33. Murata M, Tohyama S, Fukuda K: Impacts of recent advances in cardiovascular regenerative medicine on clinical therapies and drug discovery. Pharmacol Ther 2010, 126:109-118.

34. Kola I, Landis J: Can the pharmaceutical industry reduce attrition rates? Nat Rev Drug Discov 2004, 3:711-715.

35. Paul SM, Mytelka DS, Dunwiddie CT, Persinger CC, Munos BH, Lindborg SR, Schacht AL: How to improve R\&D productivity: the pharmaceutical industry's grand challenge. Nat Rev Drug Discov 2010, 9:203-214

36. The Innovative Medicines Initiative [http://www.imi.europa.eu/]

37. European Commission, Consumer Affairs [http://ec.europa.eu/consumers/ sectors/cosmetics/documents/revision/index_en.htm]

38. Amore BM, Gibbs JP, Emery MG: Application of in vivo animal models to characterize the pharmacokinetic and pharmacodynamic properties of drug candidates in discovery settings. Comb Chem High Throughput Screen 2010, 13:207-218.

39. Scott L, Eskes C, Hoffmann S, Adriaens E, Alepee N, Bufo M, Clothier R, Facchini D, Faller C, Guest R, Harbell J, Hartung T, Kamp H, Varlet BL, Meloni M, McNamee P, Osborne R, Pape W, Pfannenbecker U, Prinsen M, Seaman C, Spielmann H, Stokes W, Trouba K, Berghe CV, Goethem FV, Vassallo M, Vinardell $P$, Zuang V: A proposed eye irritation testing strategy to reduce and replace in vivo studies using bottom-up and top-down approaches. Toxicol In Vitro 2010, 24:1-9.

40. Genschow E, Spielmann H, Scholz G, Pohl I, Seiler A, Clemann N, Bremer S, Becker $\mathrm{K}$ : Validation of the embryonic stem cell test in the international ECVAM validation study on three in vitro embryotoxicity tests. Altern Lab Anim 2004, 32:209-244.

41. Wobus AM, Boheler KR: Embryonic stem cells: prospects for developmental biology and cell therapy. Physio/ Rev 2005, 85:635-678.

42. Webb S: Burgeoning stem cell product market lures major suppliers. Nat Biotechnol 2010, 28:535-536.

43. D'Amour KA, Bang AG, Eliazer S, Kelly OG, Agulnick AD, Smart NG, Moorman MA, Kroon E, Carpenter MK, Baetge EE: Production of pancreatic hormoneexpressing endocrine cells from human embryonic stem cells. Nat Biotechnol 2006, 24:1392-1401

44. Chambers SM, Fasano CA, Papapetrou EP, Tomishima M, Sadelain M, Studer L: Highly efficient neural conversion of human ES and iPS cells by dual inhibition of SMAD signaling. Nat Biotechnol 2009, 27:275-280.

45. Yang C, Yang Y, Brennan L, Bouhassira EE, Kantorow M, Cvekl A: Efficient generation of lens progenitor cells and lentoid bodies from human embryonic stem cells in chemically defined conditions. FASEB J 2010, 24:3274-3283.

46. Sharma R, Greenhough S, Medine CN, Hay DC: Three-dimensional culture of human embryonic stem cell derived hepatic endoderm and its role in bioartificial liver construction. J Biomed Biotechno/ 2010, 2010:236147.

47. Guenou H, Nissan X, Larcher F, Feteira J, Lemaitre G, Saidani M, Del Rio M, Barrault CC, Bernard FX, Peschanski M, Baldeschi C, Waksman G: Human embryonic stem-cell derivatives for full reconstruction of the pluristratified epidermis: a preclinical study. Lancet 2009, 374:1745-1753.

48. Nistor G, Seiler MJ, Yan F, Ferguson D, Keirstead HS: Three-dimensional early retinal progenitor $3 \mathrm{D}$ tissue constructs derived from human embryonic stem cells. J Neurosci Methods 2010, 190:63-70.

49. Zweigerdt $R$ : The art of cobbling a running pump - will human embryonic stem cells mend broken hearts? Semin Cell Dev Bio/ 2007, 18:794-804

50. Katsnelson A: Making lungs in the lab. Science 2012. [Epub ahead of print] 
51. O'Connor MD, MCAvoy JW: In vitro generation of functional lens-like structures with relevance to age-related nuclear cataract. Invest Ophthalmol Vis Sci 2007, 48:1245-1252.

52. O'Connor MD, Wederell ED, de longh R, Lovicu FJ, McAvoy JW: Generation of transparency and cellular organization in lens explants. Exp Eye Res 2008, 86:734-745.

53. Sharp J, Frame J, Siegenthaler M, Nistor G, Keirstead HS: Human embryonic stem cell-derived oligodendrocyte progenitor cell transplants improve recovery after cervical spinal cord injury. Stem Cells 2010, 28:152-163.

54. Lu M, Kardel MD, O'Connor MD, Eaves CJ: Enhanced generation of hematopoietic cells from human hepatocarcinoma cell-stimulated human embryonic and induced pluripotent stem cells. Exp Hematol 2009, 37:924-936.

55. Carr AJ, Vugler AA, Hikita ST, Lawrence JM, Gias C, Chen LL, Buchholz DE, Ahmado A, Semo M, Smart MJ, Hasan S, da Cruz L, Johnson LV, Clegg DO Coffey PJ: Protective effects of human iPS-derived retinal pigment epithelium cell transplantation in the retinal dystrophic rat. PLoS One 2009, 4:e8152.

56. Martin MJ, Muotri A, Gage F, Varki A: Human embryonic stem cells express an immunogenic nonhuman sialic acid. Nat Med 2005, 11:228-232.
57. Cerdan C, Bendall SC, Wang L, Stewart M, Werbowetski T, Bhatia M: Complement targeting of nonhuman sialic acid does not mediate cell death of human embryonic stem cells. Nat Med 2006, 12:1113-1114; author reply 1115.

58. Okamura RM, Lebkowski J, Au M, Priest CA, Denham J, Majumdar AS: Immunological properties of human embryonic stem cell-derived oligodendrocyte progenitor cells. J Neuroimmunol 2007, 192:134-144.

59. Nasonkin IO, Koliatsos VE: Nonhuman sialic acid Neu5Gc is very low in human embryonic stem cell-derived neural precursors differentiated with B27/N2 and noggin: implications for transplantation. Exp Neurol 2006, 201:525-529.

60. Baylis F: Geron's discontinued stem cell trial: what about the research participants? Bioethics Forum 2011. [http://www.thehastingscenter.org/ Bioethicsforum/Post.aspx?id=5640\&blogid=140]

doi:10.1186/scrt169

Cite this article as: $\mathrm{O}^{\prime} \mathrm{C}$ nnor MD: The $3 \mathrm{R}$ principle: advancing clinical application of human pluripotent stem cells. Stem Cell Research \& Therapy 2013, 4:21. 